\title{
MODIFIED GODA FORMULA TO SIMULATE SLIDING OF COMPOSITE CAISSON BREAKWATER
}

\author{
Miguel Esteban ${ }^{1}$, Hiroshi Takagi ${ }^{2}$ and Tomoya Shibayama ${ }^{3}$
}

\begin{abstract}
Caisson breakwaters can continue to maintain their function if a limited amount of sliding or tilting occurs. Although this has been the focus of much research during the last years, little attention has been paid to the design of composite caisson breakwaters (i.e. caissons protected with armour layers). The present paper outlines laboratory experiments that were carried out to propose a modification of the Goda formula (1974) that takes into account the increased pressures that can be exerted by waves due incomplete armour layers at the seaside face of the caisson. The effect that this modification can have on the expected deformations in the rubble mound after one storm are also evaluated by means of a Monte Carlo Simulation, showing how incomplete armour layers will result in much greater expected vertical movements in the caisson.
\end{abstract}

Keywords: caisson breakwater, sliding, tetrapods, incomplete armour

\section{INTRODUCTION}

Breakwaters in the past have typically been designed applying safety factors to quasi-static (standing) wave loads and static calculations for the stability against a variety of modes of failure. Wave loads are determined by choosing a design wave height which is based on return periods determined by historical statistical data. However, researchers such as Shimosako and Takahashi (1998) or Goda (1999) have highlighted problems with this traditional approach and suggest that breakwaters should be designed using a reliability-based approach. In fact, probabilistic design methods for breakwaters actually began to be researched in the mid-1980's, with Van der Meer (1988), for example, giving a probabilistic approach for the design of rubble-mound breakwaters.

Although it is clear that rubble-mound breakwaters can continue to provide shelter after taking limited damage, caisson breakwaters can also maintain their functionality if the movement of the caisson is relatively small. The most common type of movement recorded in Japan is sliding, which is not normally allowed under traditional breakwater design. This lead Shimosako and Takahashi (1999, 2000) to propose a Level 3 design method for caisson breakwaters referred to as the "deformationbased reliability design”. This model uses the Goda formula (1974) as modified by Takahashi et al. (1994) in order to obtain the wave pressures at the face of the caisson. This modification simplifies the time history of wave pressure on the caisson into a triangular "church-roof" shape (impulsive wave force) and a sinusoidal part (standing wave force). In this approach the expected sliding distance of the caisson is a statistical average of the sliding distance over the service lifetime of the structure as computed by a Monte-Carlo type simulation. The European Report PROVERBS (1999) offers a comprehensive review of the state-of-the art probabilistic breakwater design technology, including guidance on how to design breakwaters using a probabilistic approach and recommendations on how to calculate the various forces acting on the breakwater and foundations.

More recently research by Kim and Takayama (2003) and Takagi and Shibayama (2006) have proposed different improvements to the basic model of Shimosako and Takahashi (2000). These models are significant improvements over the original model of Shimosako and Takahashi (2000) and can successfully model the sliding on caisson in a number of situations, as showcased in Takagi et al. (2008). However, in all these models the displacement caused by a certain wave pressure is assumed to stay constant throughout the caisson's life. Kim and Takayama (2005) modified this model to take into account the effect of caisson tilting on the computation of sliding distance. They identified two different kinds of tilting, which they referred to as variable tilting angle $\left(\theta_{v}\right)$ and residual tilting angle $\left(\theta_{r}\right)$. The former is due to the variation of the wave moment during one wave period $(T)$ and the latter corresponds to the residual deformation (or settlement) of the rubble mound after the wave has passed. In this method an assumption needs to be made regarding the final angle of tilting of the caisson, as Kim and Takayama provide no way of estimating it. By using simple soil mechanics consolidation theory Esteban et al. (2007a) calculated the amount of settlement at the heel of the caisson, thus allowing for the calculation of the tilt in the breakwater.

Although the combination of the above models is able to provide a reasonable good estimation of the movements of a caisson breakwater, very limited research has been made on the failure mode of

\footnotetext{
${ }^{1}$ Department of Civil and Environmental Engineering, Waseda University, 3-4-1 Ookubo, Tokyo, T169-8555 Japan

2 JICA, Tokyo, Japan

${ }^{3}$ Department of Civil and Environmental Engineering, Waseda University, 3-4-1 Ookubo, Tokyo, T169-8555 Japan
} 
armoured caisson breakwaters (i.e. caisson breakwaters protected by additional armour units placed in front of them), as highlighted by the analysis of Susami West Breakwater carried out originally by Kim et al. (2005) and re-analysed by Esteban et al. (2008). In actual fact, for the case of breakwaters where one part of the breakwaters is formed of armoured caissons and the other of caissons only, the transitional area between these two sections usually suffers the greatest damage. This effect can also manifest itself for the case when the armour in front of a caisson is partially removed during a storm, and it is thus necessary to understand what effect this damaged would have on the pressures exerted by the waves on the caisson. Although the damage to the armour can be calculated using formulae such as that of Van der Meer (1998), the effect that this damage has on the computation of the forces on the caisson (by using the Goda (1974) formula for example) is not clearly understood. It is thus of vital importance to understand the amplification of wave forces that occurs in this area, and what would be the final effect after one storm. To do so, Esteban et al. (2009) carried out laboratory experiments to determine the magnification of the expected forces and proposed a modification to the Goda (1974) formula. The present paper will use this modification to evaluate the difference that this magnification of forces would have on the probabilistic deformation of the caisson's rubble mound after one storm.

\section{LABORATORY EXPERIMENTS}

Laboratory experiments were carried out by Esteban et al. (2009) with regular waves at the hydraulics laboratory of Yokohama National University in Japan to measure the load transmitted by the caisson to the gravel foundation.

\section{Apparatus}

The wave flume used measured $15.3 \mathrm{~m}$ long x $0.6 \mathrm{~m}$ wide x $0.55 \mathrm{~m}$ deep and used a piston type wave generator. Fig. 1 shows a schematic representation of the wave tank and apparatus used, which was modelled using a 1:100 scale. The water depth in the tank was kept constant throughout the experiments at $h=0.30 \mathrm{~m}$. A wave absorption beach was set at one end of the tank in order to dissipate the energy of the waves created by the overtopping of the caisson.

The dimensions of the model caisson used by Esteban et al. (2009) can be seen in Fig. 2. The mean diameter of the under-layer particles used was $10 \mathrm{~mm}$. At the beginning of each experiment the rubble mound was slightly compacted to reproduce the compaction process that would be applied to the foundations during the construction of a breakwater. This created a level foundation on top of which the caisson was placed. The caisson units were made of an outer shell of glass which was then filled with a mixture of iron sand and normal sand to ensure that the final density was similar to that of a real life concrete caisson $\left(\rho_{c}=2.0\right.$ tons $\left./ \mathrm{m}^{3}\right)$. The dimensions of the model caisson studied were $24 \mathrm{~cm}$ tall $\mathrm{x}$ $12 \mathrm{~cm}$ long x $20 \mathrm{~cm}$ wide. To the side of the caisson studied a number of other caissons were placed in order to ensure that the experiment was carried out under two-dimensional conditions. A clearance of $2 \mathrm{~mm}$ was kept between the model and the dummy caissons so that friction on either side did not occur during the experiments. No toe armour was placed on top of the rubble mound gravel. As most of the experiments were carried out with tetrapod units on top of the rubble mound, very little scouring was observed. To investigate how different layouts of armour affect the load exerted by the caisson onto the foundations, a total of 4 different configurations of tetrapod armour were used, as shown on Fig. 3 (going from an almost full layer in configuration A to no armour being present in configuration D).

Two wave gages were used in the experiment, with one being place approximately in the middle of the tank and one before just before the caisson to measure the incident wave height(see Fig. 2). This allowed for the evaluation of the change in the shape of the wave as it moved along the tank and finally hit the breakwater. The wave gages were connected to a PC, which recorded the waves as voltage signals that were later analysed to obtain the wave profiles. Esteban et al. (2007a) highlight how the load at the heel of the caisson is the critical load for determining the vertical displacement. Hence, two load cells were placed at the top of the foundations, as shown in Fig. 2. A high resolution digital camera was placed in front of the caisson to film the wave attack and identify the failure mechanism.

\section{Experimental Conditions}

Esteban et al. (2009) used a variety of regular wave types, as shown in Table 1. The Table shows the input values for the wave periods $(T)$ and wave heights that were fed into the machine, as well as the measured incident wave heights $(H)$. Also shown are the distances from the top of the caisson to the crest of the incident wave $(\eta)$. A negative value, thus, denotes a wave that has a crest higher than the caisson (i.e. that the wave was overtopping).

There were clear limitations to what types of wave could be used, as using lower values of $T$ than those shown resulted in the wave breaking mid-tank. Setting the input wave height as higher than $14 \mathrm{~cm}$ 
also resulted in the wave breaking before it reached the breakwater, which were not useful as the purpose of the experiment was to determine the effects of either unbroken or breaking waves on the caisson. Hence the experiments were not pursued with waves outside the range shown in Table 1.

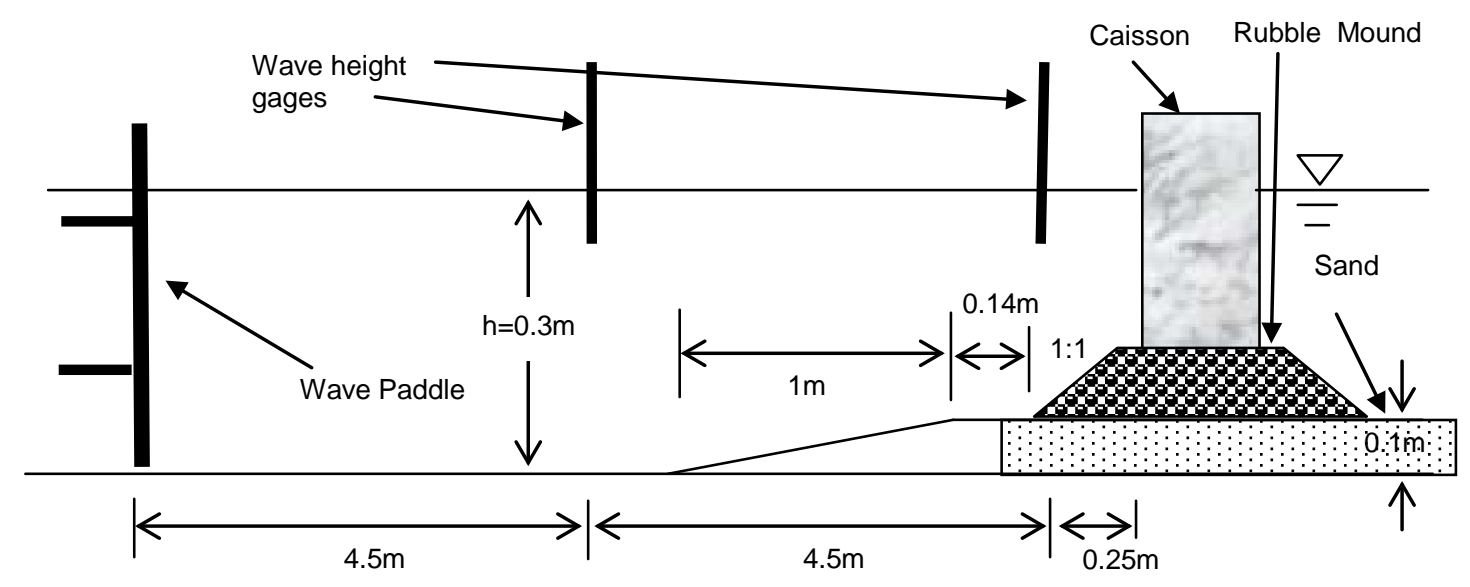

Fig.1 Experimental Set-Up

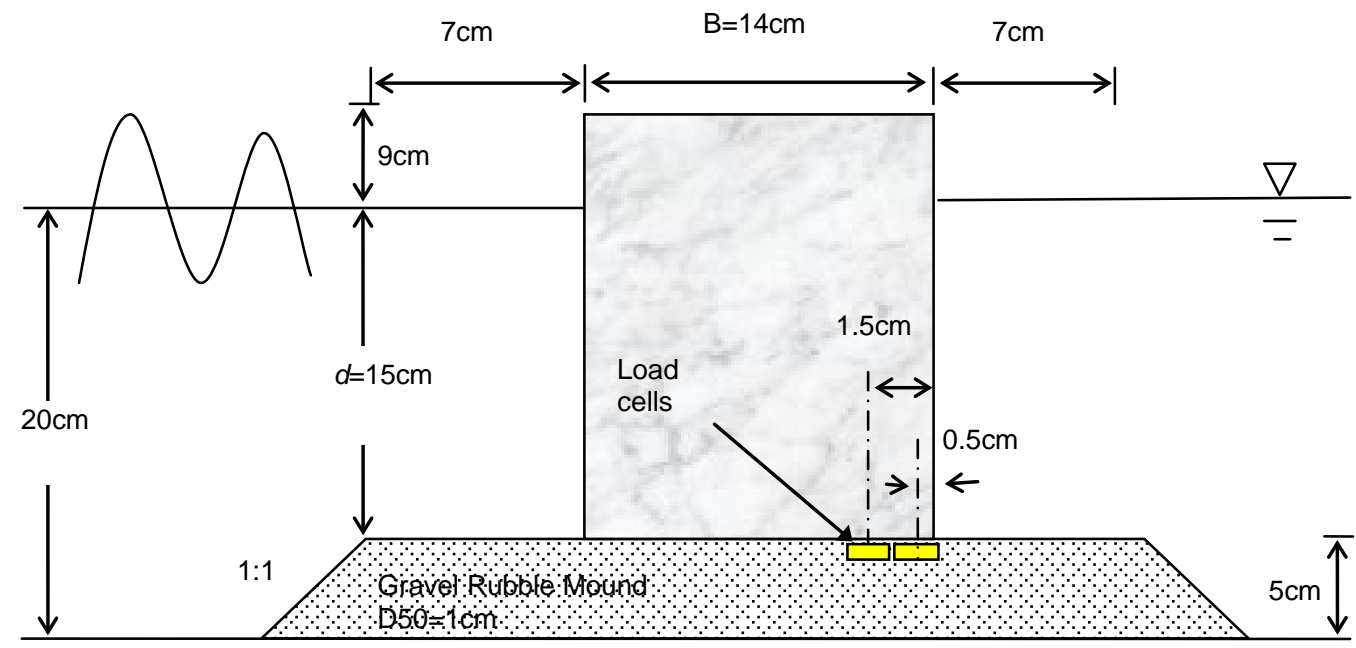

Fig.2. Layout of measuring devices.

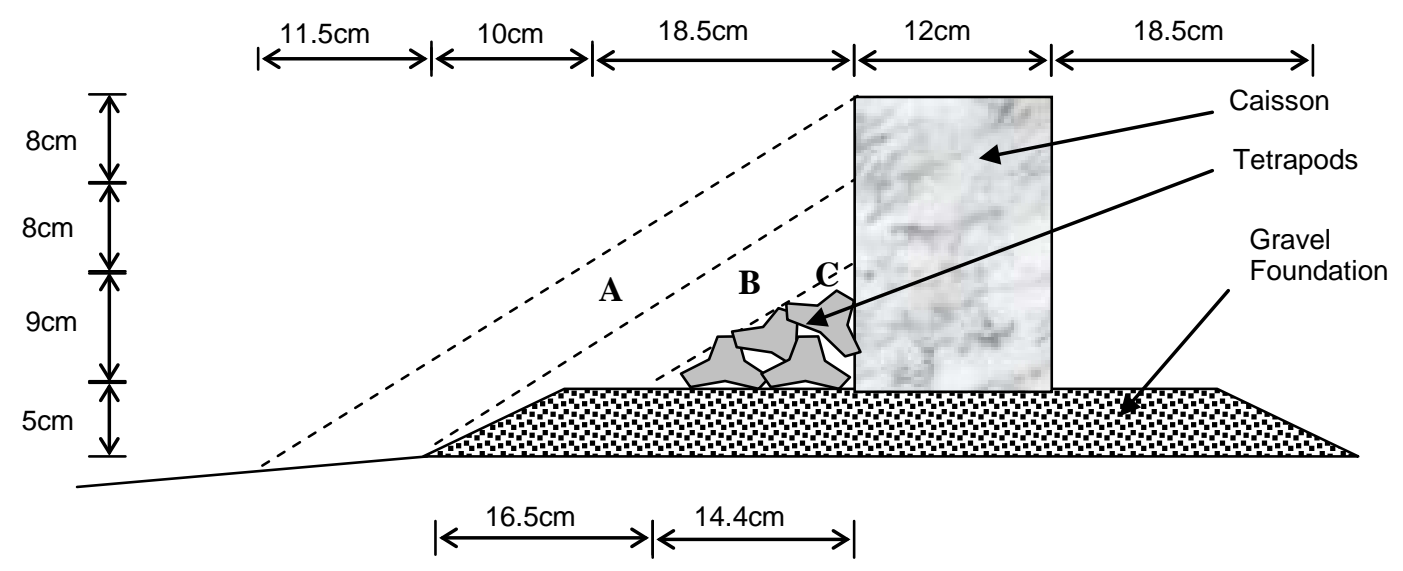

Fig.3. Dimensions of model caisson showing layout of armour layouts A-D. 
Table 1. Summary of Wave types

\begin{tabular}{|c|c|c|c|}
\hline $\begin{array}{c}\text { Wave } \\
\text { Period (s) } \\
\boldsymbol{T}\end{array}$ & $\begin{array}{c}\text { Input Wave } \\
\text { Height (cm) }\end{array}$ & $\begin{array}{c}\text { Measured Incident } \\
\text { Wave Height (cm) } \\
\boldsymbol{H}\end{array}$ & $\begin{array}{c}\text { Distance from } \\
\text { top (cm) } \\
\boldsymbol{\eta}\end{array}$ \\
\hline 0.8 & 6 & 7.04 & 1.96 \\
1 & 6 & 6.65 & 2.35 \\
1.2 & 6 & 5.59 & 3.41 \\
1.4 & 6 & 4.52 & 4.48 \\
1.6 & 6 & 4.19 & 4.81 \\
\hline 1 & 8 & 9.93 & -0.93 \\
1.2 & 8 & 8.63 & 0.37 \\
1.4 & 8 & 6.77 & 2.23 \\
1.6 & 8 & 5.53 & 3.47 \\
\hline 1.2 & 10 & 10.74 & -1.74 \\
1.4 & 10 & 8.69 & 0.31 \\
1.6 & 10 & 7.02 & 1.98 \\
\hline 1.2 & 12 & 11.11 & -2.11 \\
1.4 & 12 & 8.03 & 0.97 \\
1.6 & 12 & 6.83 & 2.17 \\
\hline 1.2 & 14 & 12.66 & -3.66 \\
1.4 & 14 & 9.95 & -0.95 \\
\hline
\end{tabular}

\section{EXPERIMENTAL RESULTS}

From the analysis of the data obtained from the load cells and the video recording, Esteban et al. (2009) classified the waves used in the experiment into 3 different groups:

- Non-breaking waves: these are waves of comparatively low $H$ and long periods, which do not break at any point before they reach the caisson. The waves exert a mainly hydrostatic force on the caisson, which result in relatively low loads that build up and dissipate gradually (see Fig. 4).

- Breaking waves: these waves break directly onto the breakwater, causing large loads to develop on the foundation. These waves are characterized by a small initial "church-like" impact shape of very small duration (see Fig. 5).

- "Overtopping waves": the crest of these waves is higher than the caisson itself (these waves are denoted by a negative $\eta$ factor in Table 1). These waves also result in large loads being applied by the caisson onto the rubble mound foundation, as can be seen in Fig. 6. In this case, the duration of the loads applied is higher than in the case of breaking waves. The loads exerted are thought to include only a fraction of the pressure component attributed to breaking waves. However, the large hydrostatic forces associated with waves of this height result in wave forces similar or higher to those of the breaking waves of the current experiment.

Figs. 7 and 8 show the maximum recorded loads for each of the armour configurations and waves used in the experiment, for breaking/“overtopping” waves and non-breaking waves, respectively. For the case of the breaking/“overtopping” waves shown in Fig. 7 the caisson exerts the highest loads on the foundation for configuration B, and lower loads for configurations A, C and D. For the case of the non-overtopping waves the second highest loads are recorded for configuration C, with configuration D and A exerting comparatively low loads. This picture starts to change as $H$ increases, with progressively higher loads recorded for configuration A. For the highest waves there is very little difference magnitude between the loadings at configurations A and B for the "overtopping” type waves.

Fig. 8 by contrast shows that low $H$ and large period non breaking waves typically exert a low load onto the foundations, usually less than $30 \mathrm{~N}$. The highest loads recorded are for armour configuration $\mathrm{D}$ (no armour at all). These loads are fairly similar to those recorded for configuration C, become lower for configuration B and are practically nonexistent for configuration A. The pressure exerted by these 
waves on the caisson is mostly hydrostatic, and these loads can be effectively dissipated by the tetrapod armour, especially in the case of an almost full armour layer (configuration A). With an increase in $H$ and decrease in wave period the energy of the waves increases, resulting in increasingly high loads exerted onto the foundations.

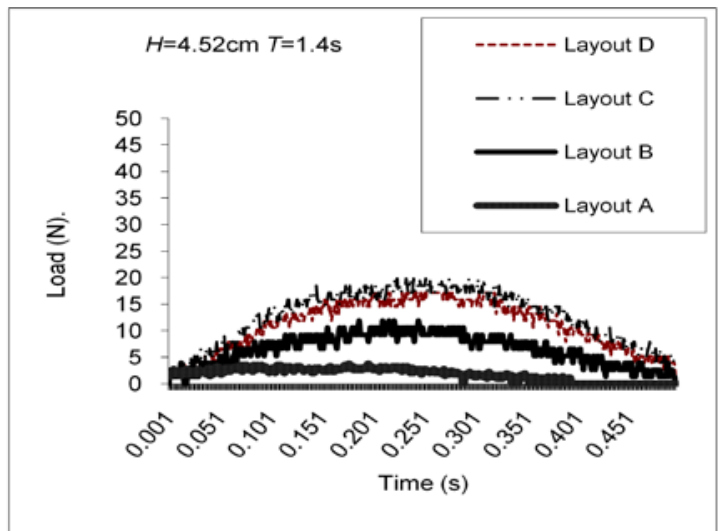

Fig. 4 Loading time history non-breaking wave

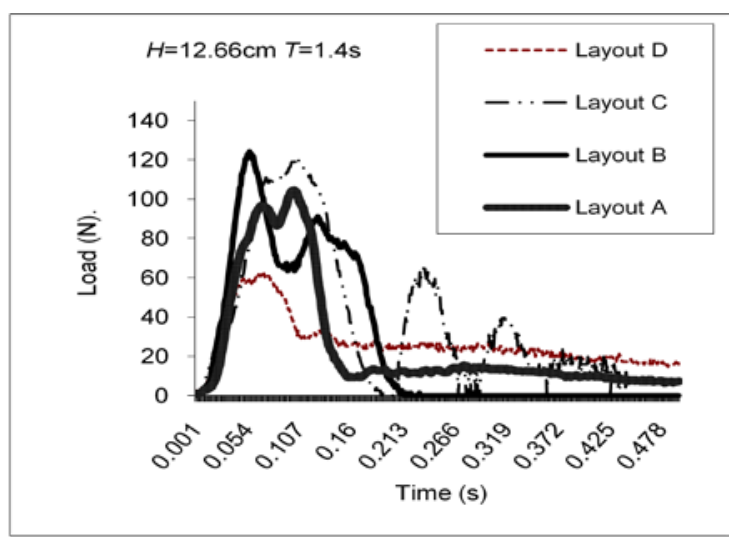

Fig. 6 Loading time history `overtopping`wave

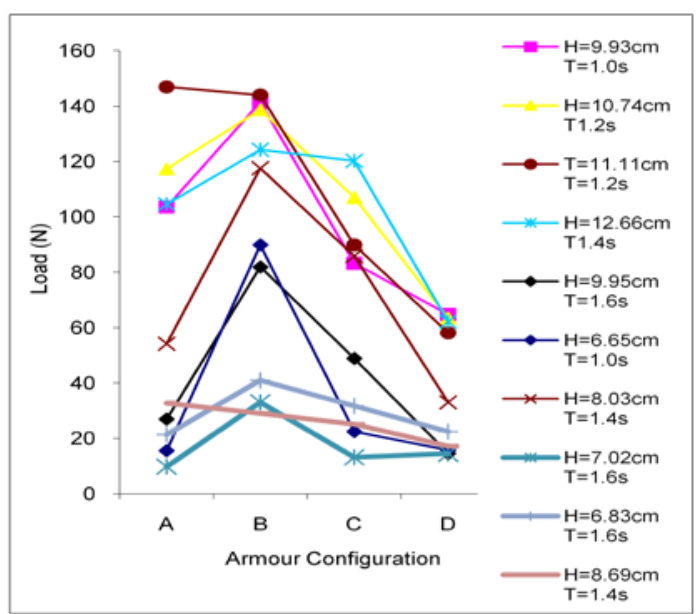

Fig. 7 Maximum loads for breaking and overtopping waves

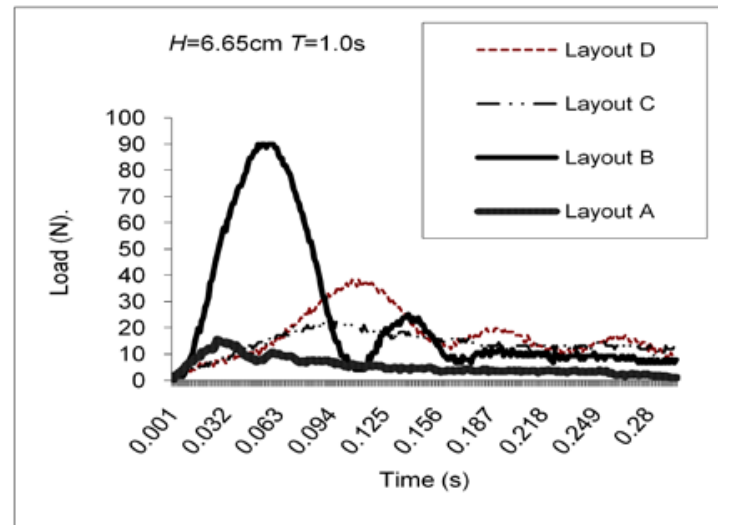

Fig. 5 loading time history of breaking waves

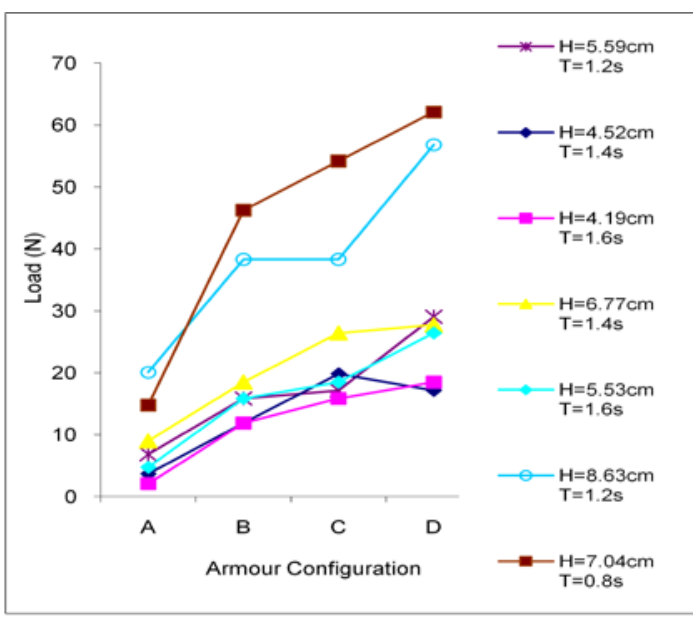

Fig. 8 Maximum loads for non-breaking waves 


\section{ESTIMATION OF CAISSON MOVEMENTS}

\section{Sliding Equation of Motion}

The forces that act on the caisson during the sliding motion can be seen on Fig. 9. Shimosako and Takahashi (2000) proposed that the equation of motion that describes the sliding should be:

$$
\left(\frac{W}{g}+M_{a}\right) \ddot{x_{G}}=P-F_{R}-F_{D}
$$

where $P$ is the horizontal wave force, $X_{G}$ the acceleration at the centre of gravity of the caisson, $M_{a}$ the added mass, $F_{R}$ the frictional resistance force, $F_{D}$ the force related sliding velocity including the wavemaking resistance force (a term that can be neglected, according to Takagi and Shibayama (2006), when the duration of the effective impact is small enough) , $W$ the caisson weight in air and $g$ the gravity

In addition, a force $F_{W}$ induced by the rotation of the caisson and the wedge of material accumulated behind the caisson due to sliding must be included:

$$
\left(\frac{W}{g}+M_{a}\right) \ddot{X_{G}}=P-F_{R}-F_{D}-F_{W}
$$

This $F_{W}$ is similar to the force $R(\theta(t))$ first introduced by Kim and Takayama (2005), which was proportional to the weight of the material above the hypothetical sliding plane of the caisson. Esteban and Shibayama (2006) proposed an alternative way to calculate this force based on the vertical deformation of the caisson and a generalized bearing capacity of the foundation gravel in the horizontal direction.

In the simplified model of Shimosako and Takahashi (2000), it is assumed that the friction coefficient $\mu$ takes a constant value i.e. it represents both the static and dynamic coefficients. Takagi and Shibayama (2006) showed quantitative evidence that $F_{D}$ can be neglected if the duration of the effective impact is small enough. Consequently the above equation can be rewritten in the form:

$$
\left(\frac{W}{g}+M_{a}\right) \ddot{x_{G}}=P+\mu U-\mu W^{\prime}-F_{W}
$$

where $W^{\prime}$ is the caisson's weight in water and $U$ is the uplift force.

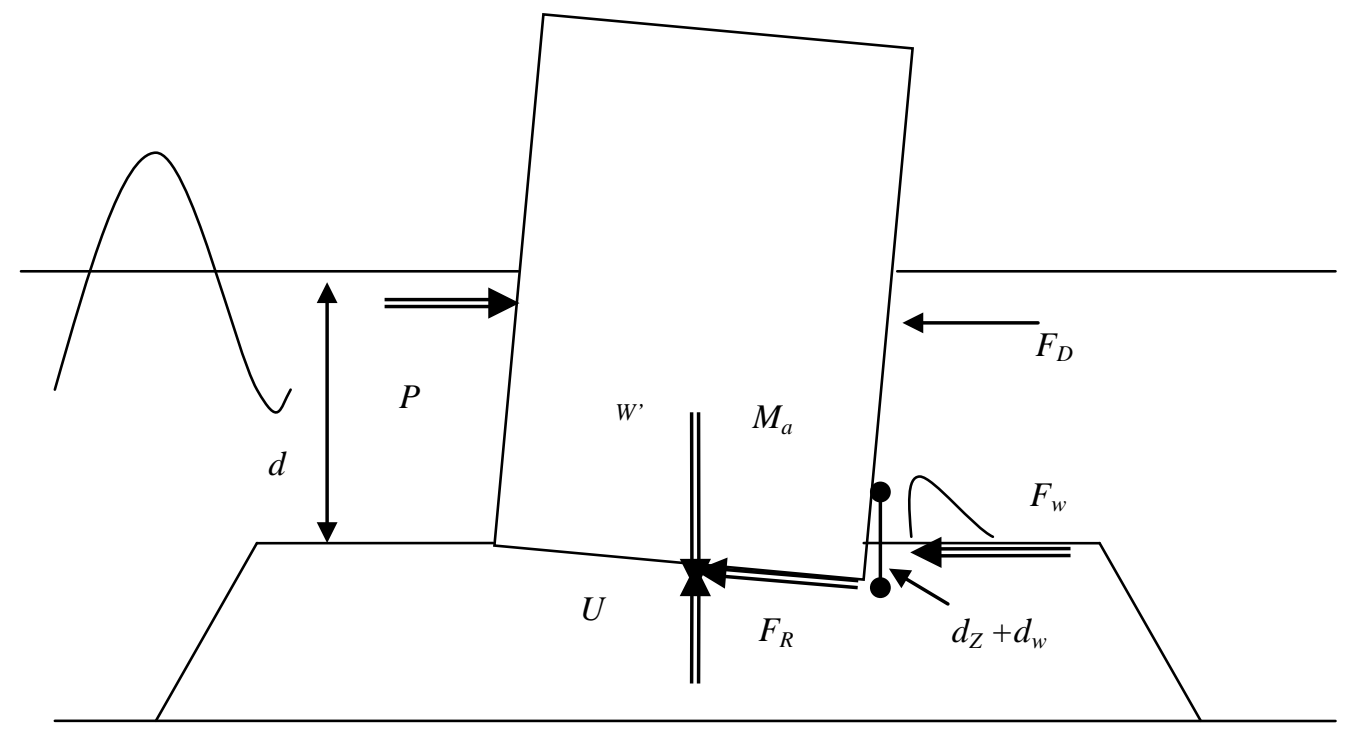

Figure 9. Forces acting on the caisson 


\section{Vertical Equation of Motion}

In order to evaluate the vertical displacement at the back of the caisson Esteban et al. (2007a) proposed a similar principle to that used by Shimosako and Takahashi (2000) to determine the sliding distance. Following the Goda formula (1974) it is generally assumed that the wave force acting on the caisson induces a triangular distribution of pressure underneath the breakwater (see Figure 10). This triangular distribution is responsible for the tilting of the caisson as it slides, as the shoreside of the foundation will take a much higher load and deform more significantly than the seaward part. Taking into account this triangular distribution, the total pressure applied to the entire foundation $P_{\text {foundations }}$ of width $B$ is given by the formula:

$$
P_{\text {foundations }}=\frac{B \cdot P_{\text {foundations.max }}}{2}
$$

and the maximum and is the maximum pressure applied to any one point, $P_{\text {foundations.max }}$,of the foundation (corresponding to the shoreside edge of the caisson) is given by

$$
P_{\text {foundations.max }}=\frac{2 \cdot P_{\text {foundations }}}{B}
$$

However, in their analysis Esteban et al. (2007a) only consider the shoreside edge of the caisson, as this area will suffer the greatest deformation. In actual fact, for the case of caissons subjected to high impact waves that are close to failing the "rocking type" movement present means that most of the pressure applied to the foundations is concentrated on a narrow strip of the foundation next to the shore (Esteban et al. 2007b). The total pressure acting on the last section (a strip of length s) of the breakwater foundation will be given by:

$$
P_{\text {last section }} \approx\left(\frac{2 \cdot P_{\text {foundations }}}{B}+\frac{W^{\prime}}{B}\right) \cdot s
$$

To obtain the motion inducing force acting on this strip of soil, the bearing capacity of the foundation needs to be deducted from the pressure applied. The equation of movement in the vertical direction thus becomes:

$$
\left(\frac{W}{g}+M_{a}\right) \ddot{X_{E}}=\left(\frac{2 \cdot P_{\text {foundations }}+W^{\prime}}{B} s\right)-q_{U} \cdot s
$$

where $\ddot{x}_{E}$ is the acceleration at the edge of the caisson and $q_{U}$ is the bearing capacity of the foundation. Or,

$$
\left(\frac{W}{g}+M_{a}\right) \ddot{X_{E}}=\left(\frac{2 \cdot P_{\text {foundations }}+W^{\prime}}{B}-q_{U}\right) S
$$

By integrating the acceleration with respect to time the velocity can be obtained and by integrating twice the vertical movement of the caisson can be calculated. 


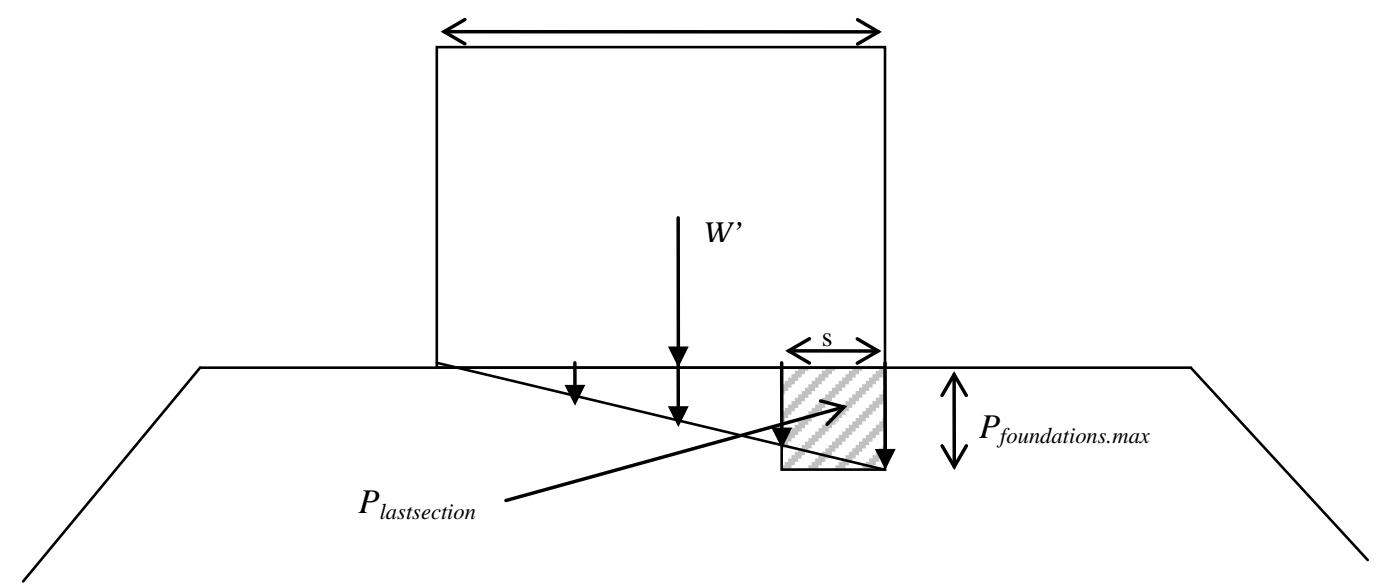

Figure 10. Diagram of Vertical Movement Parameters

\section{Wave Forces on the Caisson}

Both the models of Shimosako and Takahashi (2000) and Esteban et al. (2007) rely on the Goda formula (1974) as modified by Takahashi et al. (1994) to determine the pressure of the wave on the face of the caisson breakwater. However, this formula was not designed for an armour protected caisson breakwater, especially in the light of the findings highlighted in Figures 7 and 8. In order to correctly evaluate the failure of a caisson breakwater protected by a partially constructed damaged armour layer the Goda formula needs to be modified to include an extra parameter that takes into account this magnifying effect.

The procedure proposed by Tanimoto et al. (1996) describes how the wave force acting on the caisson can be calculated. The time history model, as shown on Figure 11, is made of the superposition of an impulsive "church-roof" shaped wave force $P_{2}(t)$, and a slowly varying standing one $P_{1}(t)$, as given by:

$$
P(t)=\max \left\{P_{1}(t), P_{2}(t)\right\}
$$

where $\tau_{0}$ is the duration of the impulsive wave. In order to calculate $P_{1}(t)$ the Goda formula is used considering only a parameter $\alpha_{1}$.To calculate $P_{2}(t)$ it is necessary to evaluate the pressure exerted by an impulsive (breaking) wave. In the formula of Goda (1974), as modified by Takahashi et al. (1994), the impulsive pressure component of the wave is given by a parameter $\alpha^{*}$, which replaces the factor $\alpha_{2}$ in the original Goda formula. This factor is defined as follows:

$$
\alpha^{*}=\max \left(\alpha_{2,} \alpha_{I}\right)
$$

where $\alpha_{2}$ denotes a coefficient indicating the effect of the impulsive pressure in the original Goda formula, and $\alpha_{\mathrm{I}}$ gives an impulsive pressure coefficient introduced by Takahashi et al. (1994).

Goda (1985) indicates how the bearing capacity of the foundation is to be analysed by means of the methodology of foundation engineering for eccentric inclined loads. However, for sites where the

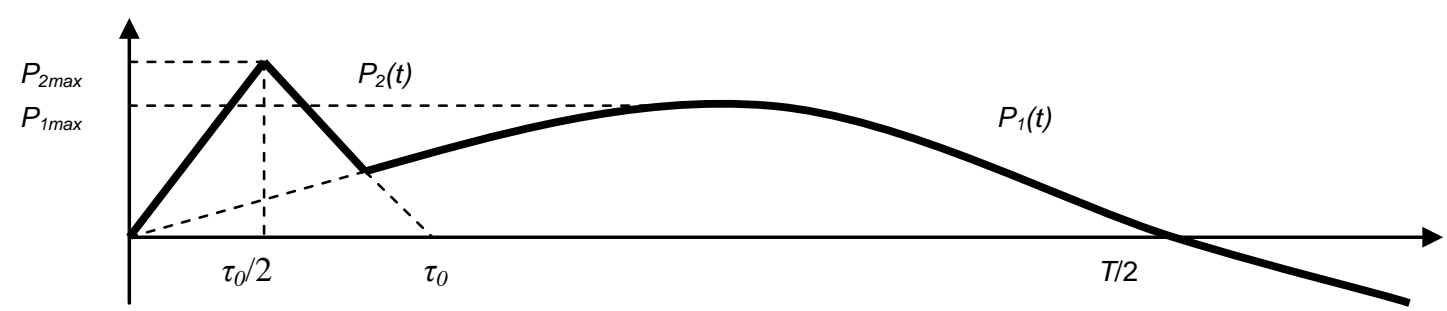

Figure 11. Wave force profile for sliding calculation 
seabed consists of a dense sand layer or soil of good bearing capacity a simplified technique of examining the magnitude of the heel pressure can be used. In this case, it is assumed that a trapezoidal or triangular distribution of bearing pressure exists beneath the bottom of the upright section, and the largest bearing pressure at the heel $p_{e}$ can be calculated by using:

$$
\begin{array}{ll}
p_{e}=\frac{2 W_{e}}{3 t_{e}} & : t_{e} \leq \frac{1}{3} B \\
p_{e}=\frac{2 W_{e}}{B}\left(2-3 \frac{t_{e}}{B}\right) & : t_{e}>\frac{1}{3} B
\end{array}
$$

in which

$$
t_{e}=\frac{M_{e}}{W_{e}}, \quad M_{e}=W^{\prime} t-M_{U}-M_{P}, \quad W_{e}=W^{\prime}-U
$$

Where $W^{\prime}$ is the weight of the caisson per unit extension in still water, $t$ the horizontal distance between the centre of gravity and the heel of the upright section, $U$ the total uplift pressure, $M_{u}$ the momentum around the heel of the caisson due to this uplift, $M_{p}$ the moment around the bottom of an upright section due to the pressure at the face of the breakwater and $B$ the width of caisson.

The results shown in Figs. 7 and 8 measured $p_{e}$, and thus Esteban et al. (2009) modified the way that this parameter is calculated to take into account the effect of partially failed armour. Hence Table 2 introduces a new parameter, $\alpha_{\mathrm{a}}$, which describes the influence of the armour on the load applied to the foundations. The values shown in Table 2 were derived by calculating how much larger were each of the loads for configurations A to $\mathrm{C}$ with respect to $\mathrm{D}$, and finding an average for each of the wave types identified. Thus, for each of the armour configurations shown in Fig. $3 \alpha_{\mathrm{a}}$ would take a different value, depending on the type of wave.

Table 2. $\alpha_{a}$ parameter map

\begin{tabular}{|l|c|c|c|c|}
\cline { 2 - 5 } \multicolumn{1}{c|}{} & A & B & C & D \\
\hline Overtopping Waves & 2.0 & 2.2 & 1.7 & 1.0 \\
\hline Breaking Waves & 1.4 & 3.3 & 1.8 & 1.0 \\
\hline Non-breaking Waves & 0.2 & 0.7 & 0.8 & 1.0 \\
\hline
\end{tabular}

Thus, eq. 3 would become:

$$
\begin{array}{ll}
p_{e}=\alpha_{a} \frac{2 W_{e}}{3 t_{e}} & : t_{e} \leq \frac{1}{3} B \\
p_{e}=\alpha_{a} \frac{2 W_{e}}{B}\left(2-3 \frac{t_{e}}{B}\right) & : t_{e}>\frac{1}{3} B
\end{array}
$$

Therefore, by using this corrected equation and the method of Esteban et al. (2007) it is possible to calculate the vertical movement of the breakwater after a given storm. The present research did not measure directly the pressure on the face of the breakwater, although it is possible to work backwards (through the Goda formula) from the load exerted at the heel to calculate the pressure at the face.

In order to use the equations outlined above, it is also necessary to know the expected armour damage, for which formulas such as that by Van der Meer (1988) can be used. 


\section{ESTIMATION OF CAISSON TILTING AFTER ONE STORM}

To investigate the effect that the proposed changes described above would have on the failure of the caisson after one whole storm a Monte Carlo Simulation was carried out for each of the four tetrapod configurations. The Monte Carlo simulation is based on the research described in Esteban et al. (2007), who measured the probability distribution functions of sliding and tilting of caisson breakwaters, and to easily compare results the dimensions of the caisson studied were kept the same. The basic layout of the breakwater would thus be similar to that shown in Figure 1, though the dimensions of the caisson itself are $20 \mathrm{~m}$ tall x $8 \mathrm{~m}$ wide $\mathrm{x} 18 \mathrm{~m}$ long. The storm was considered to be 2 hours long, and consisting of irregular waves that followed a Rayleigh distribution with deepwater significant wave height $H_{0}=6.5 \mathrm{~m}$ and $T=10 \mathrm{~s}$. The Factor of Safety (FoS) against the incident significant wave height of $\mathrm{H}_{1 / 3}=5.7 \mathrm{~m}$ was calculated to be 0.67 against sliding. A FoS of 1.2 is common in breakwater design, and generally the breakwater will not move for any storm where the $\mathrm{H}_{1 / 3}$ is lower than the design condition. Therefore, significant deformation in the rubble mound could be expected from such a storm.

The results of each of the four Monte Carlo Simulations are plotted in Figure 12. Essentially, the results for Configuration D are exactly the same to those described in Esteban et al. (2007a). However, each of the other configurations results in significant increases in the mean expected vertical movement at the back of the caisson.

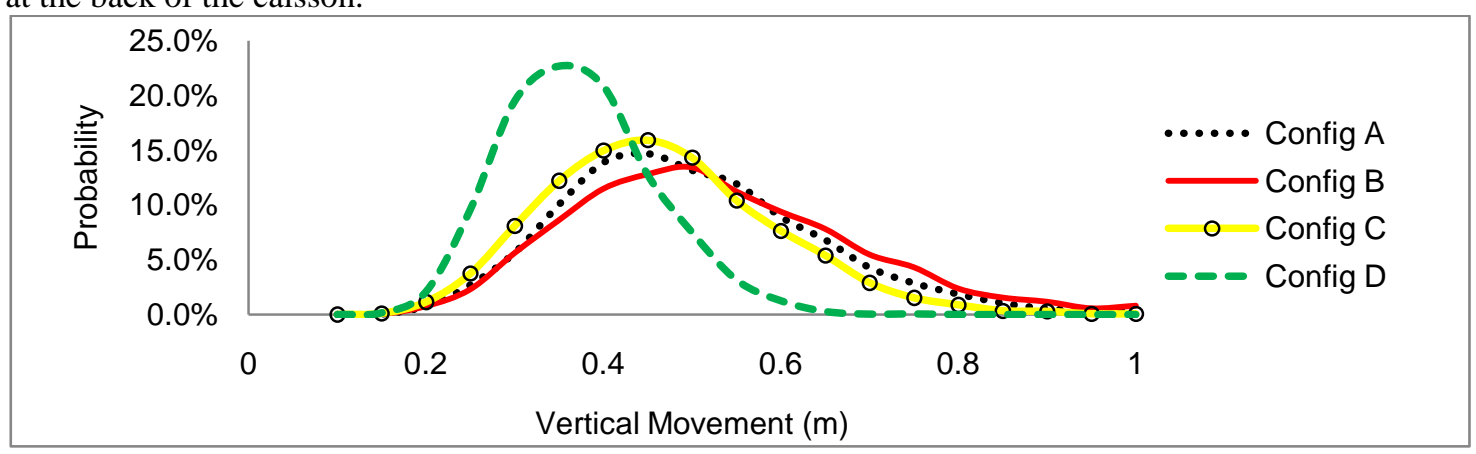

Figure 12. Probability distribution functions of vertical movement at the heel of the caisson

\section{DISCUSSION}

It was expected that the loads exerted by the caisson onto the foundation for an incomplete armour layer would be higher than for the case were no armour was present. It has been observed by Japanese engineers that often the areas of transition between composite and caisson breakwaters (i.e., the area where an armoured protected breakwater turns into a caisson breakwater, with the amount of armour gradually reducing) often suffers more damage than the non-transition areas during a storm. This effect has received little attention from researchers in the past, though it is very important to determine the failure of a caisson breakwater protected by partially failed, half constructed or transition areas in the armour layers. The estimation of the correct load exerted by the wave on the foundations of a caisson breakwater is essential for the calculation of the vertical movement of the caisson into the rubble mound (or "tilting"), as shown by Esteban et al. (2007a). Most of these vertical deformations occur as a result of impulsive breaking waves, or overtopping waves, as shown in the current research. Hence the correct evaluation of these pressures is of great importance, and these can increase substantially due to the effect of incomplete armour layers. Figs. 7 and 8 show how it is thus important for the practising engineer to determine which type of loading can be expected, and whether the crest of this wave will be higher than the caisson ("overtopping" wave) or not.

Figs. 4, 5 and 6 show how the shape of the wave at the time when it hits the caisson clearly affects the load time history. Non-breaking waves exert mainly hydrostatic pressure, while breaking waves exert the characteristic "church-roof” loading. For some waves (such as that shown in Fig. 5), certain tetrapod configurations (B in this case) induce this "church-roof" shape, which are not present in the other armour configurations. Thus, it is clear that partially failed armour layers can induce breaking on a wave that would otherwise not be as damaging to the breakwater. In these cases it is important whether the waves break on the caisson directly or into the armour, as the armour can successfully dissipate some of the energy of the waves (as seen in configuration A in Fig. 5) 
For the case of "overtopping” waves, the presence of armour makes the wave pile even higher on top of the breakwater, and produces even higher loads than when little or no armour is present (see Fig. 6). However, in this case there is little difference between configurations A and B, as the crest of the wave is higher than the caisson, and hence waves break just above the caisson, mitigating the breaking wave effect. This explains the difference in the shape of the wave between "church-like” peaks of Figs. 5 and the irregular peaks of Fig. 6.

It should also be noted that configuration A does not correspond to a full armour layer, as in the present study the top of the layer had only one unit (see Fig. 3). It is probable that if a much wider tetrapod layer was present at the top of the breakwater the wave forces would have been significantly reduced in all configuration A wave cases. Hence even configuration A should be considered to be an "incorrectly" or "damaged” armour layer configuration.

There were a number of difficulties in carrying out these experiments. The load measured by the load cell does not always return to 0 at the end of the wave. This possibly indicates that displacements in the rubble mound are subjecting the load cell to a higher pressure than it was originally withstanding. It is quite difficult to know from what point the instrument started to over-estimate the pressure which is applied by the wave. Also, there is the possibility that the instrument was overrecording during part of the wave and then returned to its original condition due to further deformation in the rubble mound. Each experiment was clearly analysed, and some experiments where the load cell clearly did not function properly were removed from the final results.

Also, although great care was given to building identical tetrapod layers between each of the experimental conditions, the nature of tetrapod placing ensured that no two layers were exactly identical. During some experiments, movements of individual tetrapod units were observed. The authors believe that these do not directly affect the results, as the movements were generally of isolated units, and the shape of the wave appears to remain constant independent of these movements.

The classification of the waves was carried out by analysing slow-motion videos of the waves as they hit the breakwater and a great deal of information was obtained by the careful analysis of these videos. However, sometimes it was difficult to assess the exact point at which the waves were breaking, and the effect of this on the loading on the foundation. A more sensitive camera, coupled with maybe a device to measure the velocity of the water would have been useful to further clarify the failure mechanism.

There were laboratory limitations in the range of waves that could be used. For example, for the range of wave heights shown in Table 1, very few experiments could be carried out with a $T$ of less that $1.0 \mathrm{~s}$, as these often resulted in the waves breaking in mid-tank, which confounded the loading analysis. Also, the number of armour configurations studied was comparatively limited. The range of application of the model presented is thus relatively limited and should be followed by more detailed studies on different experimental layouts and wave types.

Another limitation of the present experiments is the limited scale $(1: 100)$ on which they were carried out. Unfortunately due to laboratory limitations it was not possible to carry out these experiments on a bigger scale, and it is clear that scale effects could somewhat confound the application of the method shown in this paper into real life design. Furthermore, the values given for $\alpha_{\mathrm{a}}$ in Table 2 were based on a relatively limited number of experiments, and it would be necessary to repeat them for a wider variety of situations to obtain a more accurate estimation of these parameters. As they stand at present they can only be considered indicative of what could be expected, and caution is recommended in their use.

The results shown in Fig. 12 show a shifting of the mean expected vertical displacement from those computed in configuration D to higher displacements in other configurations. The spread of the probability distribution function also increases, resulting in a wider range of values and a longer "tail", meaning that the probability of "catastrophic" failure increases substantially.

Future work should focus on clarifying the effect of wave overtopping. To do so it is recommended that a high-speed camera is used, and that the experiments are carried out at a higher scale. Also, the current work did not determine the pressure at the face of the breakwater, and although it is possible to work backwards from the loading at the heel to determine the pressures at the wall, these should nevertheless be verified independently.

The present model has so far not been compared to cases of real-life failures, and it thus lacks validity. Care should be exercised at this point in using the modifications proposed. The authors will attempt to validate the model against real-life failures in the future. 


\section{CONCLUSIONS}

The present paper investigated the failure mechanism of various configurations of armoured caisson breakwaters against waves of a variety of heights and periods by carrying out experiments in a wave flume at Yokohama National University, Japan. Using a camera the waves were classified into three different types, namely non-breaking, breaking and "overtopping", with the load cells under the caisson providing data on the characteristic loadings of each type of wave. The load time histories obtained showed how the pressure applied by a caisson onto the foundations differs depending on the configuration of armour situated in front of the breakwater and the type of wave. For non-breaking waves the highest loads were recorded for the case where no armour was present, though for the other cases the highest loads were recorded for a slightly damaged layer, where the armour was just above the mean water level. For the case of "overtopping" waves the loads for a slightly damaged (just above water level) and a "complete" armour layer were not significantly different.

Using the results of the laboratory experiments a new parameter was introduced to modify the way that the Goda formula (1974) calculated the loads exerted by the caisson onto the rubble mound foundations. Using this modification a Monte Carlo Simulation was carried out to determine the difference that could be expected after one storm in the vertical deformations at the back of the caisson between the 4 different armour configurations proposed. It was found that the presence of an incomplete armour layer significantly increased the mean and range of expected vertical deformations.

The results clearly highlight the need for engineers to pay close attention to the design of armour in front of a caisson breakwater. Incorrectly designed armour, or transition zones between areas with and without armour, can greatly affect the stability of the caisson (which could otherwise be more stable without the presence of any armour). Although this paper has shed some light into the failure mode of composite breakwaters further research is needed to better understand their failure mode and to compare the results presented to cases of real-life caisson failures.

\section{ACKNOWLEDGMENTS}

This work was supported by the grant in aid for scientific research, No. (B) 22404011 of the Japan Society for the Promotion of Science (JSPS).

\section{REFERENCES}

Esteban, M., and Shibayama, T. (2006). "Laboratory Study on the Progression of Damage on Caisson Breakwaters Under Impact Waves.” Techno-Ocean $/ 19^{\text {th }}$ JASNAOE Ocean Engineering Symposium, Kobe.

Esteban, M., Takagi, H. and Shibayama, T. (2007a). Improvement in Calculation of Resistance Force on Caisson Sliding due to Tilting. Coastal Engineering Journal, Vol. 49, No.4 (2007) pp 417-441

Esteban, M., Takagi, H. and Shibayama, T. (2007b). Evaluation of the Active Depth of Foundations Under a Caisson Breakwater Subjected to Impact Waves. Coastal Structures 2007 International Conference, Venice

Esteban M. and Shibayama T. (2008) Computational Estimation of Caisson Sliding and Tilting of Susami West Breakwater due to Typhoon Tokage, 33rd Annual Journal of Civil Engineering in the Ocean, JSCE, Japan.

Esteban M., Takagi H. and Shibayama T. (2009) Modification of the Goda Formula to Evaluate the Movement of a Caisson Breakwater Protected by Failed Armour, Proc. Of Coasts, Marine Structures and Breakwaters 2009, 16-18 Sept, Edinburgh, UK.

Goda, Y. (1974). New wave pressure formulae for composite breakwater, Proc. 14th Int. Conf. Coastal Engineering, Copenhagen, ASCE, pp.1702-1720.

Goda, Y. (1985). Random Seas and Design of Maritime Structures. University of Tokyo Press.

Goda, Y. (1999). Wave Actions and Damage on Maritime Structures, Lecture Note at DHL-JICA Seminar, Ankara, Turkey.

Kim, T.M., Takayama, T. (2003). Computational Improvement for Expected Sliding Distance of a Caisson-Type Breakwater by Introduction of a Doubly-Truncated Normal Distribution, Coastal Engineering Journal, Vol.45, No.3 (2003) 387-419.

Kim, T.M., Yasuda, T., Mase, H. \& Takayama, T. (2005) Computational Analysis of Caisson Sliding Distance Due to Typhoon Tokage, Asian and Pacific Coasts Conference 2005, pp 565-576.

Kim, T.M., Takayama, T. \& Miyawaki, Y. (2004) Laboratory Experiments on the Sliding Distance and Tilting Angle of a Caisson Breakwater Subject to Wave Impact, Proc. 29th Int. Conf. on Coastal Eng., ASCE, pp 3762-3773. 
PROVERBS (1996-1999). Various authors. Commission of the European Union (EU): Probabilistic Design Tools for Vertical Breakwaters (PROVERBS) - concept paper 1996-1999; MAST contract MAS3-CT95-0041; Leichtweiss Institut für Wasserbau, Braunschweig, 1999

Shimosako, K., and Takahashi, S. (1998). Reliability design method of composite breakwater using expected sliding distance. Report of the Port and Harbour Research Institute 37, 3, pp. 3-30 (in Japanese)Losada, Spain, Balkemare, pp. 363-371.

Shimosako, K., and Takahashi, S. (1999). Application of deformation-based reliability design for coastal structures -Expected sliding distance method of composite breakwaters -. Coastal Structures '99, ed. I.J. Losada, Spain, Balkemare, pp. 363-371.

Shimosako, K. \& Takahashi, S. (2000). Application of Expected Sliding Distance Method for Composite Breakwaters Design, Proc. $27^{\text {th }}$ Int. Conf. on Coastal Eng., ASCE, pp 1885-1898.

Takagi, H. and Shibayama, T. (2006). A new approach on performance-based design of caisson breakwater in deep water, Annual Journal of Coastal Engineering, JSCE, Vol.53, pp.901-905 (in Japanese)

Takagi, H., Esteban, M. and Shibayama, T. (2008). Proposed methodology for evaluating the potential failure risk for existing caisson breakwaters in a storm event using a level 3 reliability based approach. Proc. of 31st International Conference on Coastal Engineering (ICCE 2008), Hanover, Germany.

Takahashi,S., Tanimoto, K. \& Shimosako, K. (1994) A Proposal of Impulsive Pressure Coefficient for Design of Composite Breakwaters, Proc. of the International Conference of Hydro-Technical Engineering for Port and Harbour Construction:489-504

Tanimoto, K., K. Furakawa and H. Nakamura (1996). Hydraulic resistant force and sliding distance model at sliding of a vertical caisson, Proc. Coastal Engineering, JSCE 43:846-850 (in Japanese).

Van der Meer, J.W. (1988). Deterministic and Probabilistic design of a breakwater armour layers. $J$. Waterway Port Coastal Ocean Eng. ASCE, 114, 1, pp 66-80. 